\title{
Application of Recycled PET Fibers for Concrete Floors
}

\author{
Sudhira De Silva and T. Prasanthan
}

\begin{abstract}
High consumption of plastics leads to production of large amounts of plastic waste. Plastic is non-biodegradable so its disposal has been a problem. In order to resolve this problem, recycled PET fibers were proposed to be used as reinforcement in concrete. This paper has discussed the effect of adding Polyethylene terephthalate (PET) fiber to the blended cement mixed concrete floor slab panel. This research consists of two main stages. In first stage, different volumes of recycled PET fibers, i.e. $0 \%, 0.5 \%, 1.0 \%$ and $1.5 \%$ have been added as percentages of concrete by volume. The results showed that the maximum volume of PET fiber for a desired compressive and tensile strength was $1.0 \%$. It was observed that $15.3 \%$ of increase in compressive strength, $22.44 \%$ of increase in flexural strength and $18.77 \%$ of increase in split tensile strength for the addition of $1.0 \%$ PET fibers to the concrete. In second stage, optimum fiber percentage $(1.0 \%)$ selected from the first stagewas used to produce slab panels. Inorder to investigate the structural performances of the slab panel, center-point line loading test, dropping weight test and energy absorption test were conducted. It has been found that recycled PET fiber introduced slab panels showed better performance compared to the conventional floor slab panel.
\end{abstract}

Keywords: $\quad$ Recycled PET, PET Fiber Reinforced Concrete, Concrete Foof Slab, Permeability of Concrete

\section{Introduction}

High consumption of plastics leads to the production of large amounts of plastic waste in world. Discarded polythene and plastics are one of the increasingly important problems encountered in waste management. These wastes are not biodegradable, and remain in the environment once disposed them. Treatment method of plastics through incineration process will release toxic gases to the environment that could be harmful to human health. Plastic-recycle process is one of the acceptable solution for above problem. The highest percentage (93\%) of recyclers use PP (polyethylene terephthalate) as a raw material in plastic recycling industry compared to other polymers (Gunarathna et al 2010) in Sri Lanka.

Even though concrete has many versatile properties, there are some drawbacks in the concrete. When compare with some of the typical building materials concrete has a relatively low tensile strength, low ductility and it is susceptible to cracking. In-order improve these mechanical properties of concrete, various researches are being conducted by researchers. From past experimental works, it was found that addition of recycled PET fibers to concrete showed significant improvement in concrete mechanical properties (Sandaruwani et al, 2012) [5]. However, there is no research found in literature that focus on the addition of recycled PET fibers with Blended cement to further enhance the mechanical properties of concrete.

Blended cement provides number of benifts compare to Ordinary Potland Cement (OPC) in current construction industry. The heat of hydration of Portland Pozzolana Cement (PPC) is lower than that of OPC. Hence it is best choice for mass concreting. Also PPC has higher fineness than OPC, resulting for higher durability. Blended cement is environmentally friendly because it utilises the by-product from the coal fired thermal plants. Therefore it is green material, hence ecofriendly and helpful in achieving green rating. Overall, PPC is cheaper and more sustainable as compared to OPC. The main drawback of PPC is less setting time and less initial strength compare to OPC. However, these drawbacks not highly affect the preparation of concrete floor slab panels.

\footnotetext{
Eng. (Dr.) Sudhira De Silva, PhD (Saitama), MEng (Saitama), PG Diploma (Strut), B.Sc. Eng. (Hons) (Moratuwa), C.Eng. MIE (Sri Lanka), Senior Lecturer, Department of Civil and Environmental Engineering, University of Ruhuna, Sri Lanka.

Email:sudhira@cee.ruh.ac.lk

(D) ORCID ID: $h$ ttp://orcid.org/0000-0003-0804-5097

Eng. T. Prasanthan, B.Sc. Eng. (Hons), A Lanka)Engineer, National Housing Development Authority, Sri Lanka.

Email:prasanthan1301@gmail.com

D ORCID ID: $h t t p: / / o r c i d . o r g / 0000-0002-3278-0174$
} 
The application of reinforced concrete floor slab panels are very common in most of industry floors (mechanical floors) where heavy machinery are expected to install. Industry floors needed special design requirements due to utilize of large amount of concrete \& steel, required highergrade concrete and higher energy \& thermal absorbation capacity. Thereby designers are expected to control floor vibrations induce from heavy machineries.

Also certain floor slab panels are subjected to high number of impacts so increase the impact resistance of floor slab panel also necessary need. Therefore, analyzing the structural performance and suitability of PET fiber reinforced concrete floor slab panel is required before implementing it in industry floors.

Fraternali (2011) conducted an experiment to determine the compressive strength of PET fiber reinforced concrete and identified that it has an improvement in the compressive strength compare to normal concrete. Also, it has been identified that compressive strength was increased with the increment of PETfiber diameter. Short PET fibers give higher compressive strength than the long PET fibers. Marthong (2015) identified that there is a reduction of compressive strength as the volumetric fiber percentage increases beyond $0.5 \%$. Additionally, it was declared that compressive strength also varies with the geometry and the dimensions of PET fibers.

Ochi (2006) conducted uniaxial compression test and identified that compressive strength of PET fiber reinforced concete (FRC) was increased with the fiber content increased up to $1 \%$. Further increased of PET fiber content caused decrease in compressive strength of concrete. Similar to the Ochi's findings, Sandaruwani et al (2012) identified that similar variation in compressive strength of PET FRC. Their study revealed that compressive strength increases with increase of fiber content upto a maximum of $1 \%$ and then the compressive strength is decreasing with the increment of fiber content more than that.

Marthong (2015) findings, it was found that the inclusion of PET fiber above $1.0 \%$ decreases the tensile strength of concrete. The inclusion of PET fiber improved the tensile capacity of concrete and showed the ability in absorbing energy in the post-cracking state due to the bridging action imparted by the fibers during cracking. However, Sandaruwani (2012) identified that fiber content can be increased up to $2 \%$ with an improvement in the tensile capacity. It was revealed that the tensile capacity was reduced as the fiber content increase beyond $2 \%$. Rathnayaka (2015) conduct an experiment to determine compressive and split tensile strength of PET fiber reinforced concrete and identified that it has been reduction in compressive strength compare to normal concrete but there is an improvement in tensile strength up to $3 \%$ of PET fiber content. However, there is no study on application of PET fiber with blended cement concete in industry floor slabs.

Therefore, the possibilitiy of using waste plastic fiber as a reinforcement material in blended cement mix concrete to produce floor slab panel has been investigated through current study. Objectives of the study were to investigate the appropriate mix proportions and resultant variations in strength characteristics of PET fiber reinforced blended cement mix concrete made with short PET fibers and to identify the structural suitability of PET fiber and blended cement mixed concrete floor slab panel to industry floors.

\section{Methodology}

\subsection{PET FRC Sample Preparation}

Re-cycled PET fibers obtained from The Beira Enviro Solutions (Pvt) Ltd., Horana, Sri Lanka was introduced in to the concrete mixes. PET fiber was added on the volume basis, and it would not replace any material in the concrete. Table 1 shows details of mix proportions. Fibers were added in $0 \%, 0.5 \%, 1 \%$, and $1.5 \%$ of total volume to investigate the mechanical properties of the concrete mix.

Table 1 - PET FRC Sample Preparation

\begin{tabular}{|c|c|c|c|c|}
\hline Sample & $\begin{array}{c}\text { Fiber } \\
\text { diameter } \\
(\mathrm{mm})\end{array}$ & $\begin{array}{c}\text { Fiber } \\
\text { length } \\
(\mathrm{mm})\end{array}$ & $\begin{array}{c}\text { Water/ } \\
\text { Cement } \\
\text { ratio }\end{array}$ & $\begin{array}{c}\text { PET } \\
\text { fiber } \\
\text { percent } \\
\text { age (\%) }\end{array}$ \\
\hline A1 & 0.7 & $50 \pm 5$ & 0.3 & $0 \%$ \\
\hline A2 & 0.7 & $50 \pm 5$ & 0.3 & $0.50 \%$ \\
\hline A3 & 0.7 & $50 \pm 5$ & 0.3 & $1.00 \%$ \\
\hline A4 & 0.7 & $50 \pm 5$ & 0.3 & $1.50 \%$ \\
\hline
\end{tabular}

\subsection{Experimental Procedure}

The experiment was conducted in two main stages. In first stage, different volumes of recycled PET fibers, i.e. $0 \%, 0.5 \%, 1.0 \%$ and $1.5 \%$ (Table 1) have been added as percentages of concrete by volume and the compressive, split tensile and flexural strength tests were performed to identify the optimum fiber percentage.

Compressive strength of concrete was tested using cube of 150x150x150 mm dimension. Cubes were casted according to BS 1881-108 (1988) and 
cured until the test day as described in BS1881111(1988). Concrete was mixed based on the mix design in accordance with BS 5328 (Part 2:1997) and target design strength of concrete was 50 $\mathrm{MPa}$. In order to achieve a workable mix, admixture "Optima 100" was added to the concrete mix. Slump was evaluated for each set of specimen on the day of mixing before casting the cubes (BS 1881-102). These specimens were crushed at the age of 7,14 and 28 days (Figure 1(a)). Compressive strength was measured in accordance with BS 1881-115 (1988) and BS 1881116 (1988).

Cylindrical specimens of $150 \times 300 \mathrm{~mm}$ were casted to test split tensile strength of concrete as shown in Figure 1 (b). Beam specimens of $100 \times 100 \times 500 \mathrm{~mm}$ were casted to test flexural strength of concrete and it is measured in accordance with BS EN 12390-5 (2000) as shown in Figure 1 (c).

\begin{tabular}{|c|c|}
\hline Table 2 - Concrete Mix Design \\
\hline Material & Quantity \\
\hline Cement & $500 \mathrm{~kg} / \mathrm{m}^{3}$ \\
\hline Fine Aggregates & $840 \mathrm{~kg} / \mathrm{m}^{3}$ \\
\hline Coarse Aggregates & $910 \mathrm{~kg} / \mathrm{m}^{3}$ \\
\hline Water & $150 \mathrm{~kg} / \mathrm{m}^{3}$ \\
\hline W/C & 0.3 \\
\hline $\begin{array}{c}\text { Admixture } \\
\text { (Optima -100) }\end{array}$ & $2.75 \mathrm{~kg} / \mathrm{m}^{3}$ \\
\hline
\end{tabular}

Note: Specific gravity of the coarse aggregate -2.65 , The percentage of passing $600 \mu \mathrm{m}$ sieve of the fine aggregates $32 \%$, Dosage of admixture $-1.1 \mathrm{~kg}$ per $100 \mathrm{~kg}$ of cementation materials
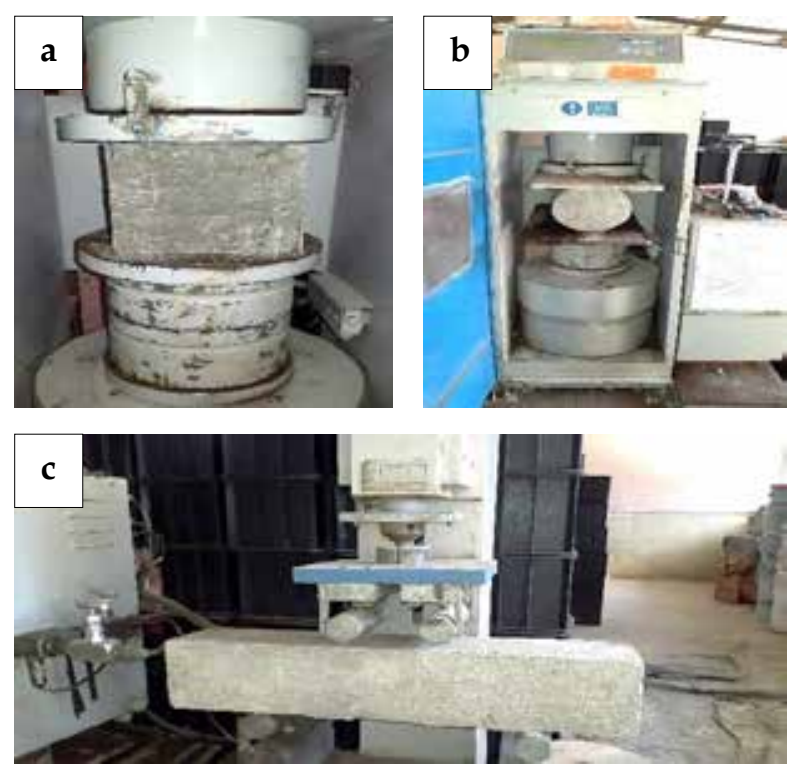

Figure 1-Testing of Specimens; (a) Compressive Strength Test, (b) Split Tensile Strength Test, (c) Flexural Strength Test
In the Stage 2, structural suitability of floor slab panel was investigated. In order to perform the test, optimum fiber percentage (i.e, 1\%) found from the Stage 1 was used to prepare the specimen in Stage 2. Concrete slab panels were casted as shown in Figure 2. Following factors were considered in the selection of the economical size of the slab panels.

- Testing method and size of the available apparatus

- Handling capabilities of the slab panel

- Economies of constructing

- General size used in literature

By considering above factors, floor area of $500 \times 500 \mathrm{~mm}$ and thickness of $100 \mathrm{~mm}$ slab panel was selected.

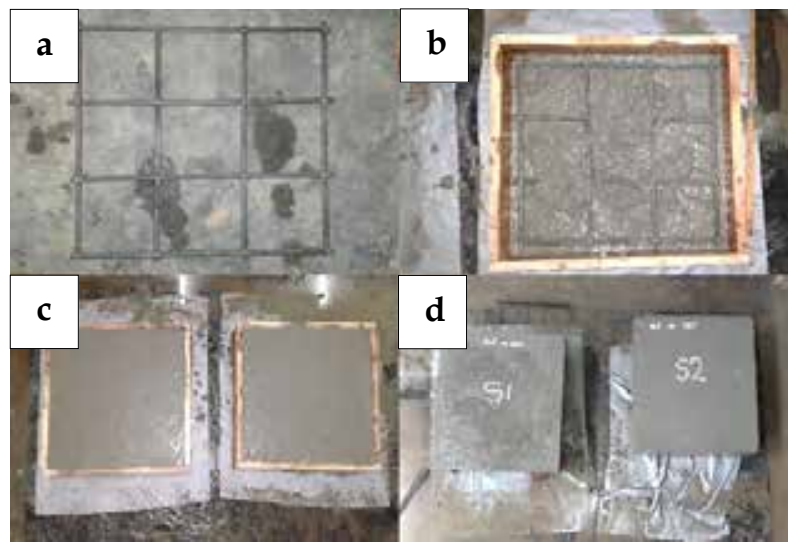

Figure 2 - Preparation of Slab Panel; (a) Reinforcement Arrangement, (b) and (c) Pouring of Concrete, (d) Curing of Slab Panel

In order to investigate the structural suitability of slab panel, impact resistance, flexural strength, and energy absorption capacity were investigated.

The impact resistance was determined by conducting dropping weight test (ACI Comitte 544). This test yields the number of blows necessary to cause prescribed levels of distress in the test specimen. This number serves as a qualitative estimate of the energy absorbed by the specimen at the levels of distress specified. The test was used to compare the relative merits of different fiber-concrete mixtures and to demonstrate the improved performance of FRC compared to conventional concrete. The instrument setup for the drop-weight test is shown in Figure 3. The low velocity impact resistance test was conducted and the impact resistance is represented by number of blows until first crack appear in the surface of the slab panel. 


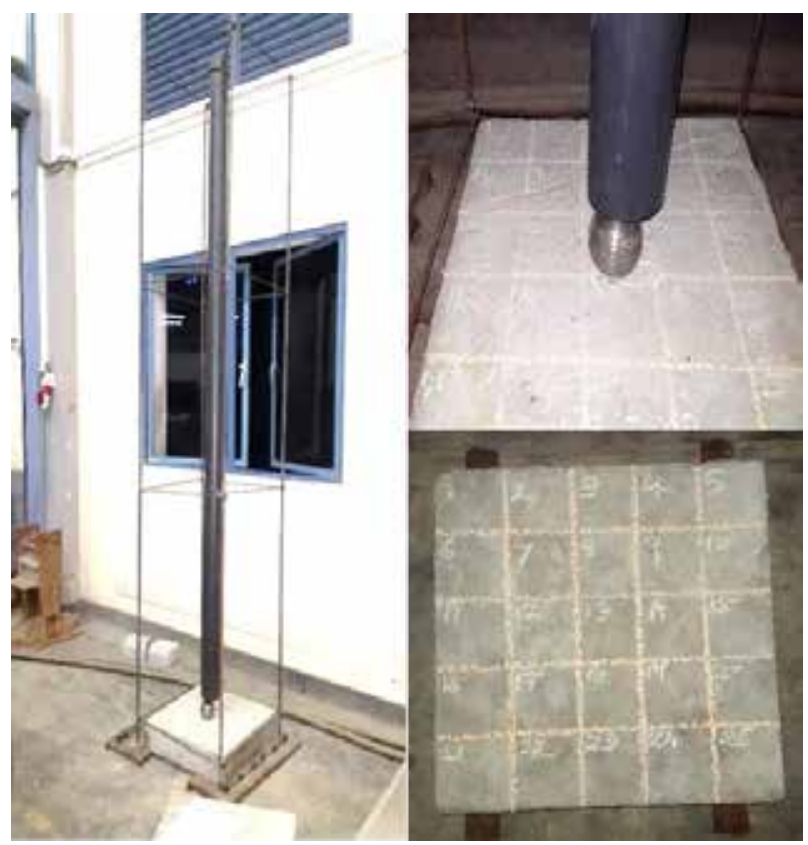

Figure 3 - Instrumental Set-up for the Impact Resistance Test

The flexural strength of slab panel was measured by conducting Centre-point line loading test according to ASTM C293. Figure 4 shows loading setup for the slab panel and static load was apllied through the accuator. Applied load, deflection and crack propergation monitored and recorded during the test.

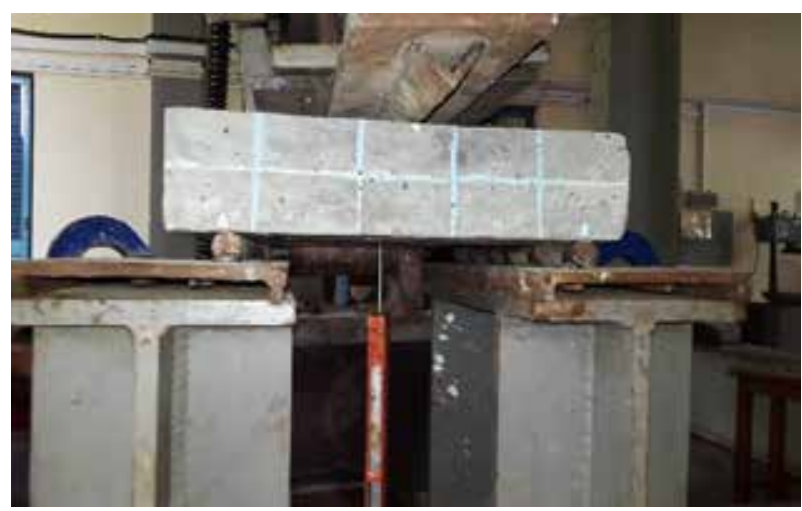

Figure 4 - Loading Arrangement for the Slab Panel

Energy absorption capacity of recycled PET reinforced concrete slab panel was compared with normal reinforced slab panel by measuring floor vibration to impact. Instrumental arrangement for the energy absorption experiment is shown in Figure 5. Slab panel was supported on the knife edge support and uniform impact was given to slab panel by using a mallet. The floor vibration was measured by using a seisomogaph.

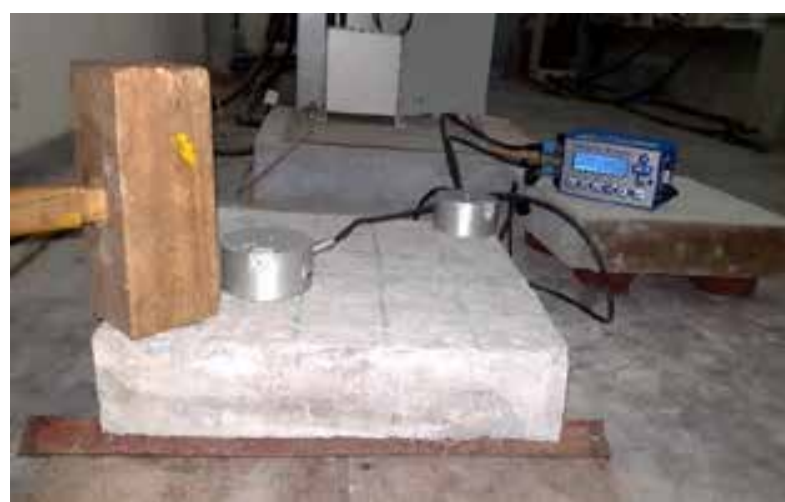

Figure 5 - Instrumental Set-up for the Energy Absorption Test

To determine the durability characteristics of recycled PET fiber introduced concrete, water permeability test was conducted. The test was carried out according to German Standard DIN 1048 on concrete specimens of size 150x150x150 $\mathrm{mm}$, at the age of 28 day. The test was performed for the conventional concrete sample and PET fiber introduced blended cement mix concrete sample.

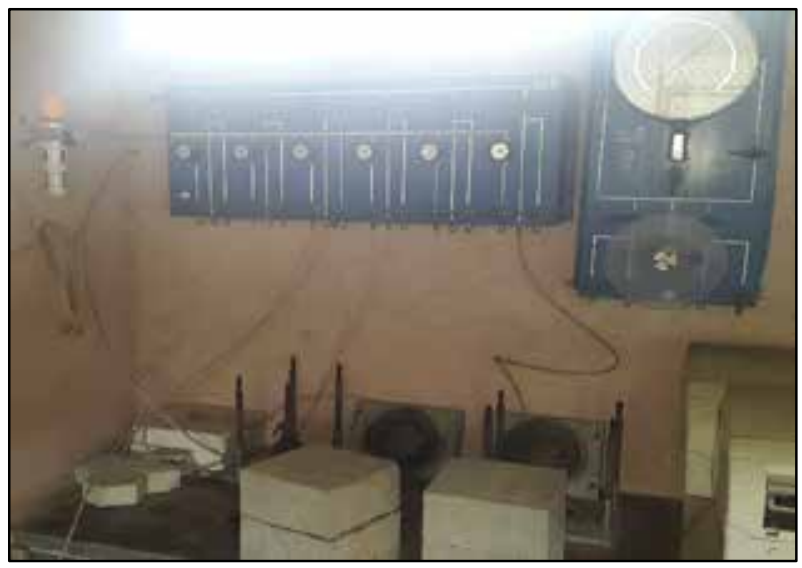

Figure 6 - Permeability Test Setup

\section{Results and Discussion}

\subsection{Variation of Compressive Strength with PET Fiber Content}

Figure 7 shows variation of compressive strength with PET fibercontent. For a blended cement mix PET fiber concrete mixers show a significant improvement in compressive strength. This results compared with previous studies by Sadaruwani et al., (2012) and Rathnayake et al. (2015) by using OPC mixers. It revealed that $0.5 \%$ and 1\% PET fiber specimen's are having higher compressive strength than that for the control specimen. Further increase in fiber content, resulted to reduce the compressive strength 
significantly. PET fiber can increase the compressive strength of concrete up to certain limit of fiber content due to confinement of the fiber reinforcement in concrete. With higher fiber content, workability of concrete was reduced to such an extent that even admixture may not help to maintain homogeneity of the concrete mixer. If concrete cannot be compacted properly due to lack of workability and homogeneity, increase of fiber content in concrete leads to decrease in compressive strength of concrete.

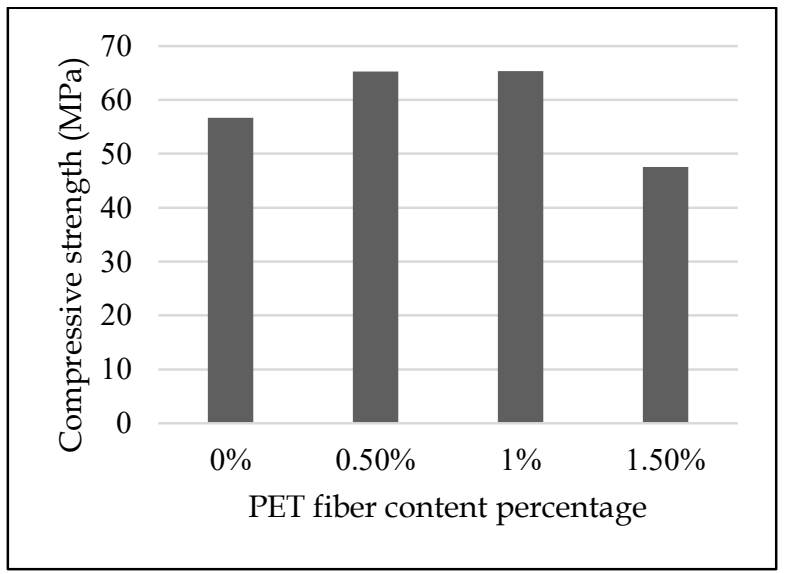

Figure 7 - Variation of Compressive Strength with PET Fiber Content

\subsection{Variation of Flexural Strength of Concrete with PET Fiber Content}

Figure 8 shows variation of flexural strength of concrete for different PET fiber content. It was identified that flexural strength of PET fiber introduced concrete is higher than that in the control specimen. It can be observed that there is an improvement in the flexural strength of concrete when increasing the PET fiber content due to the bridging action imparted by the fibers during cracking.

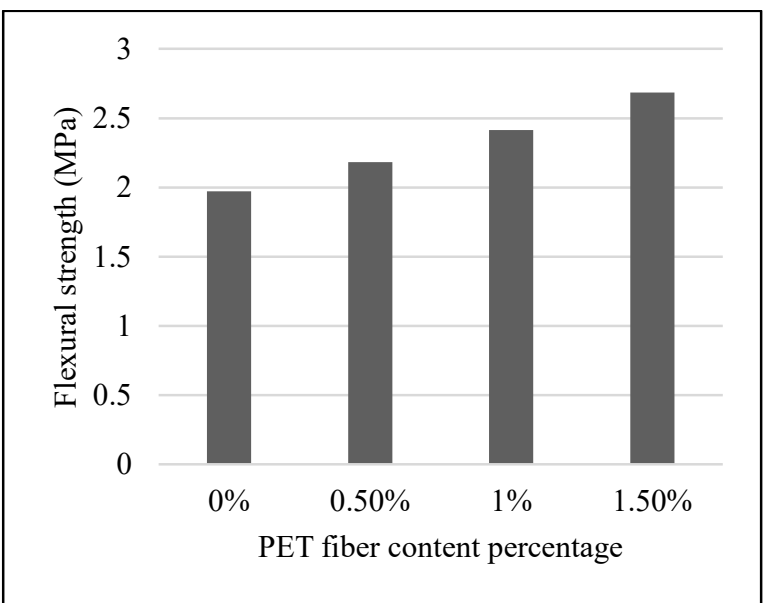

Figure 8 - Variation of Flexural Strength of Concrete for Different PET Fiber Content

\subsection{Variation of Tensile Strength of Concrete with PET Fiber Content}

Figure 9 shows variation of splitting tensile strength of concrete with increasing PET fiber content. It revealed that spliting tensile strength of concrete increased with PET fibercontent and higher than that of the control specimen. It can be observed that there is an improvement in the flexural strength when increase of PET fiber content due to the bridging action imparted by the fibers during cracking. Figure 8 indicates the improvement of tensile strength of concrete with different proportion of PET fiber.

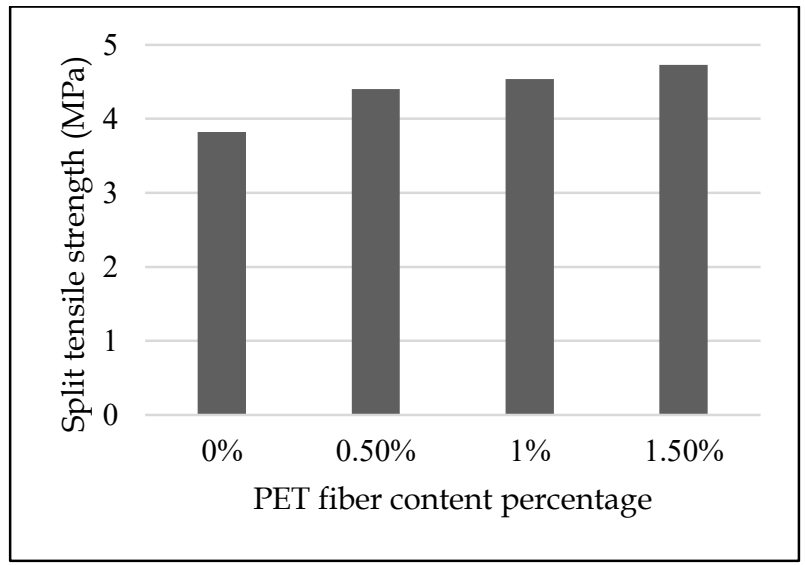

Figure 9 - Variation of Splitting Tensile Strength with PET Fiber Content

\subsection{Variation of Concrete Workability with PET Fiber Content}

To determine the workability of concrete, slump value of the concrete was measured. As the fiber is introduced to the concrete, the slump value of the concrete starts to reduce as shown in Figure 10. This is due to increase of fiber content in mix cause to increase of surface area from the fibers. In addition to the coarse aggregate, the mortar must also coat with the fibers. If the mix's mortar friction is insufficient, then the effect on the slump and workability is greater.

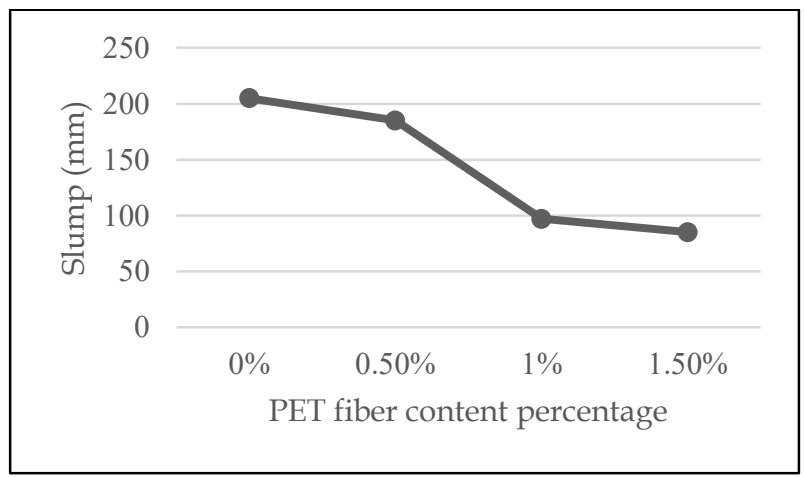

Figure 10 - Variation of Slump of Concrete with PET Fiber Content 


\subsection{Impact Resistance of Slab Panels}

The number blows required to appear first crack in the slab are shown in Table 3. It was observed that the maximum value of the number of blows to cause a first crack was 72 blows for Recycled PET fiber introduced concrete slab panel while number of blows to cause a first crack in control slab panel was 31 . This indicates that the impact resistance of fiber introduced concrete slab panel is increased by $132.25 \%$ compare to the conventional slab panel.

Table 3 - Impact Resistance of Slab Panel

\begin{tabular}{|c|c|}
\hline Slab panel & $\begin{array}{c}\text { Number of blows } \\
\text { to first crack }\end{array}$ \\
\hline $\begin{array}{c}\text { 0\% PET fiber reinforced } \\
\text { concrete slab panel }\end{array}$ & 31 \\
\hline $\begin{array}{c}\text { 1\% PET fiber reinforced } \\
\text { concrete slab panel }\end{array}$ & 72 \\
\hline
\end{tabular}

\subsection{Flexural Strength of Slab Panels}

It has been noticed that the load at first crack of fiber concrete slabs improves by the addition of Recycled PET fiber and increases up to $7.98 \%$ for $1.0 \%$ by volume at a period of 28 days. Significant improvement in ductility ratio was observed for the Recycled PET slab panel compare to conventional slab panel (Refer Table 4). However, the ultimate failure load for the Recycled PET slab panel is $43.51 \%$ lower than the conventional reinforced slab panel.

\subsection{Energy Absorption of Slab Panel}

Floor vibration of Recycled PET reinforced concrete slab panel was compared with conventional reinforced slab panel (Figure11).

Table 4 -Flexural Testing of Slab Panel

\begin{tabular}{|l|c|c|}
\hline Property & $\begin{array}{c}\text { 1\% PET fiber } \\
\text { introduced slab } \\
\text { panel }\end{array}$ & $\begin{array}{c}\text { 0\% PET fiber } \\
\text { introduced slab } \\
\text { panel (Control) }\end{array}$ \\
\hline Failure mode & Ductile & Ductile \\
\hline $\begin{array}{l}\text { Load at first } \\
\text { crack (kN) }\end{array}$ & 61.13 & 56.61 \\
\hline $\begin{array}{l}\text { Ultimate Load } \\
(\mathrm{kN})\end{array}$ & 99.37 & 142.61 \\
\hline Ductility ratio & 0.488 & 0.343 \\
\hline
\end{tabular}

Table 5 shows the root mean square (rms) value of the floor accereation for both slab panels. It can be observed that dissipation of energy in Recycled PET fiber reinforced concrete slab panel is quicker than the normal reinforced concrete slab panel, indicating that slightly higher damping available with the Recycled PET fiber reinforced concrete slab panel.

Table 5 - RMS value for the Slab Panels

\begin{tabular}{|c|c|}
\hline Slab panel & rms value $\left(\mathbf{m m} / \mathbf{s}^{2}\right)$ \\
\hline $\begin{array}{c}0 \% \text { PET fiber reinforced } \\
\text { concrete slab panel }\end{array}$ & 4854 \\
\hline $\begin{array}{c}1 \% \text { PET fiber } \\
\text { reinforced concrete } \\
\text { slab panel }\end{array}$ & 4620 \\
\hline
\end{tabular}

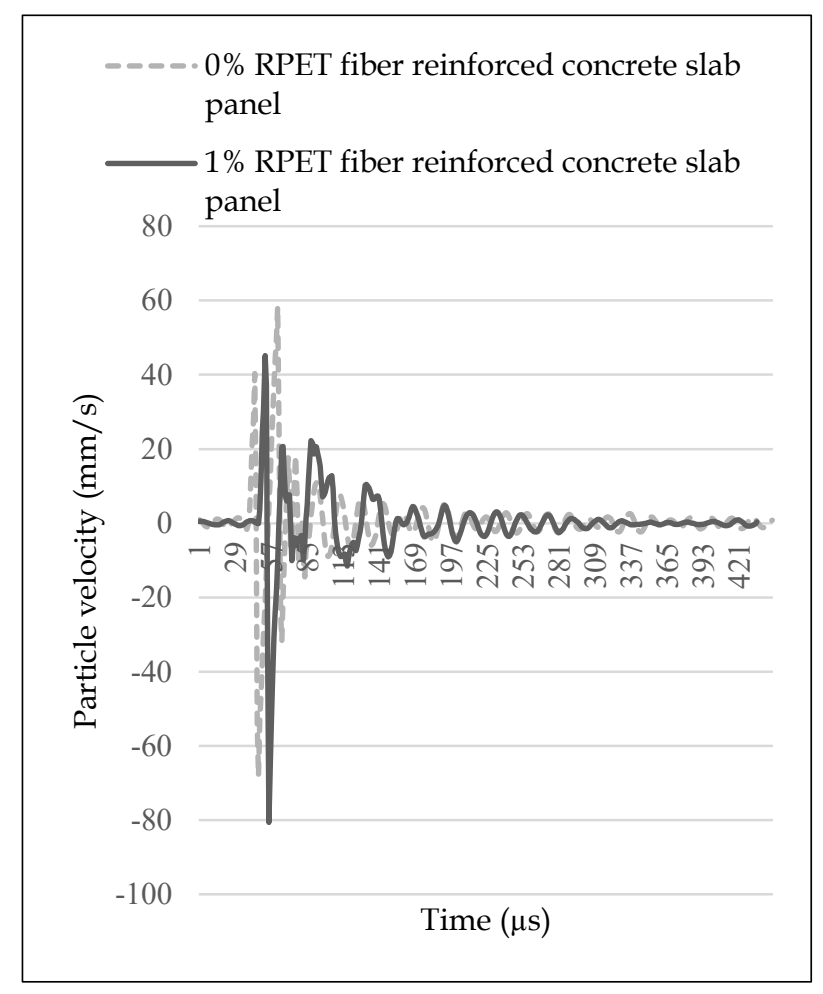

Figure 11- Energy Dissipation in the Slab Panel

\section{Conclusions}

By considering the compressive, flexural and tensile strength of recycled PET fiber introduced concrete and workability of the mix, $1 \%$ PET fibercontent was found as optimum value for the ben-ded cement mixed concrete floor slab panel.

The additions of $1.0 \%$ (by volume) of Recycled PET fiber improved the impact resistance by increase the energy absorption capacity of the slab panel. Recycled PET fiber introduced slab panel has high flexural capacity until first crack appeared. This is due to high ductility capacity of PET fiber reinforced concrete. Ultimate failure load for the Recycled PET slab panel is lower than the conventional reinforced slab panel. Higher damping properties seems to be exsisted 
with PET fiber introduced slab panel than the conventional reinforced slab panel, indicating contribution of energy absorbing ability of PET fibers into the slab pannels. Therefore it is revealed that PET fiber introduced concrete floor slab has more advantages to use in mechanical floors in Ground Floor levels without adding much steel reinforcement.

\section{Acknowledgement}

The authors wish to thank Beira Enviro Solutions (Pvt) Ltd., Sri Lanka for support extended in the preparation of Recycled PET fibers. The authors are also immensely grateful to Siam City Cement Lanka (Pvt) Ltd for the support extended to conduct laboratory testing

\section{References}

1. Gunarathna, G. P. N., Bandara, N. J. G. J. \& Liyanage, S., "Analysis of Issue and Construction Associated with Plastic Recycling Industry in Sri Lanka", Department of Forestry and Environmental Science, University of Sri Jayewardenepura, Sri Lanka, 2011.

2. Fernando Fraternali a, Vincenzo Ciancia, Rosaria Chechile, GianvittorioRizzano, Luciano Feo,. "Experimental Study of the Thermomechanical Properties of Recycled PET Fiberreinforced Concrete", Composite Structures, 93(9), 2011, pp. 2368-2374.

3. Coming starful Marthong, Shembiang Marthong, "An Experimental Study on the Effect of PET Fibers on the Behaviour of Exterior RC BeamColumn Connection Subjected to Reversed Cyclic Loading", Online Research Journal of the Institution of Structural Engineers.

4. Ochi T., Okubo S.\& Fukui K., "Development of Recycled PET Fiber and its Application as Concrete-Reinforcing Fiber",Cement and Concrete Composites, 29(6), 2007, pp. 448-455.

5. Sandaruwani, A. H. W. E.,Bandara, K. A. J. M.\& De Silva, S., "Investigation on Mechanical Behaviour of Concrete with Fibers Made of Recycled Materials", Proceedings of International Conference on Structural Engineering and Construction Management, December, 2012, paper no.SBE/12/81.

6. Rathnayaka, R. M. M. P., Malshan, W. V. D., De Silva Sudhira \& De Silva Subashi, "Incorporating Recycled PET Fibres for Concrete Cylindrical Culverts", Proceedings of International Conference on Structural Engineering and Construction Management, December, 2015, paper no.SECM/15/135. 